\title{
Self-efficacy support in senior computer interaction
}

\section{Henk Herman Nap*, H. Paul de Greef and Don G. Bouwhuis}

\author{
Human-Technology Interaction, \\ Technische Universiteit Eindhoven, \\ TU/eDen Dolech 2, \\ Eindhoven, The Netherlands \\ E-mail: h.h.nap@smart-homes.nl \\ E-mail: h.p.d.greef@tue.nl \\ E-mail: d.g.bouwhuis@tue.nl \\ ${ }^{*}$ Corresponding author
}

\begin{abstract}
Self-efficacy of seniors could be negatively affected by stress during computer interaction, yet, empirical evidence is lacking. In an experiment, seniors performed tasks on low- and high-complexity search systems. Self-efficacy was manipulated by performance feedback. Results demonstrate that negative feedback increases stress and decreases self-efficacy. Furthermore, positive feedback increases seniors' self-efficacy during computer interaction and a significant effect was found of self-efficacy on stress. Perceived stress increased with decreasing self-efficacy. System complexity influenced self-efficacy; yet, no relation was found between system complexity and stress. To increase self-efficacy and to decrease stress in senior-computer interaction, it is advised to support seniors during computer interaction with positive performance feedback.
\end{abstract}

Keywords: self-efficacy; support; seniors; stress; computer interaction; elderly.

Reference to this paper should be made as follows: Nap, H.H., de Greef, H.P. and Bouwhuis, D.G. (2013) 'Self-efficacy support in senior computer interaction', Int. J. Cognitive Performance Support, Vol. 1, No. 1, pp.27-39.

Biographical notes: Henk Herman Nap received his MSc degree in Cognitive Ergonomics at Utrecht University and a PhD degree at Eindhoven University of Technology. The research during his $\mathrm{PhD}$ focused on stress in senior computer interaction. After his $\mathrm{PhD}$ he worked as a postdoctoral research fellow on senior gamers at the Game Experience Lab of Eindhoven University of Technology. He published journal and conference papers on Gerontechnology and gaming research. Currently he works as a researcher and project leader at 'Stichting Smart Homes', in European and national projects related to senior computer interaction, rehabilitation gaming, persuasive technologies, eHealth, and smart living.

H. Paul de Greef received a PhD degree in Psychology from the University of Amsterdam. Since 1984 he worked as researcher at the Social Science Informatics department in Amsterdam, Since 1990 as Assistant Professor at the Social Science Informatics department of the University of Leiden, and since 1999 he has a position as Assistant Professor user-centered design at Eindhoven University of Technology. He has a longstanding experience 
in Cognitive Ergonomics and design of computer support for normal users in stressful conditions. Currently his interests centre on computer support and user-interface design for the elderly and the disabled.

Don G. Bouwhuis is Emeritus Professor of Cognitive Engineering at the University of Technology, Eindhoven. He specialises in the analysis and development of interaction dialogues and ergonomic evaluation procedures and associated methodology. From 1990 onwards he has been involved in the evaluation of research in the European Framework programmes on disabled and elderly, and people with special needs. He was co-founder of the International Society of Gerontechnology, and has written a course on Cognitive Aspects on Ageing which appeared as a COST publication. Currently he concentrates on predictive models for the adoption and usage of telecare products.

USAB 2010: HCI in Work \& Learning, Life \& Leisure, Klagenfurt University, 16.-17. September 2010.

\section{Introduction}

Populations are ageing rapidly, particularly in Europe and Japan (UN, 2008), while the world is becoming more digitised. Aging affects general changes (declines) in perception, cognition and movement control, which have an influence on learning and using digitised systems (Morrell et al., 2002; Neerincx et al., 2000; Xie, 2002). Seniors have been found to be slower than young adults on information retrieval tasks (Freudenthal, 2001; Nap, De Greef, and Bouwhuis, 2005), on 3D navigation using desktop systems (Sayers, 2004), and on web navigation (Neerincx et al., 2000). Not having access to or not being able to use digitised systems may put older adults at a disadvantage in terms of their ability to live independently (Czaja and Lee, 2007). Especially for less mobile seniors, the PC and internet can provide them with a means to communicate with others and gather information without mobility constraints, but this is only possible if the means provide high accessibility. To decrease the complexities seniors face in the use of these systems, design and engineering should be performed in close consideration of the knowledge and capabilities of seniors. Another necessary ingredient of satisfying interaction is self-efficacy (Bessière et al., 2006). In a survey study of managers and professionals (Compeau and Higgens, 1995) it was found that computer self-efficacy has a significant influence on individuals' outcome expectancies of using computers and on their anxiety about using computers. A lack of self-efficacy may even hinder adoption of new technology.

Feeling competent or having confidence in one's skills in a specific situation is a central concept in different theories of behaviour regulation. It is covered in Bandura's (1977) concept of self-efficacy. Self-efficacy is the belief in one's ability to succeed in specific situations. It influences the challenges a person takes as well. A similar self-confidence concept in the Cognitive Activation Theory of Stress (CATS) (Ursin and Eriksen, 2004) is outcome expectancy, i.e., a personal expectation of performance of the task at hand. The expected task performance is a subjective estimate of one's own level of performance or one's own subjective estimate of how likely one is to succeed, which refers to the individual appraisal of the situation. The appraisal process occurs in two stages; primary appraisal of the way a person construes the significance of an encounter 
for his or her well-being (Lazarus and DeLongis, 1983), and secondary appraisal, when various coping options are evaluated, such as altering the situation or accepting it (see Folkman et al., 1986). According to Ursin et al. (1978), coping is the trust in one's own abilities to perform, and it influences perceived fear and stress responses.

The level of self-efficacy, or expected task performance, regulates which tasks one may repeat and which tasks one tends to avoid. Successful mastery of a task increases the level of self-efficacy, failure lowers it, and a low level of self-efficacy is associated with avoidance of the task and according to CATS, causes a stress response when task engagement cannot be avoided. High self-efficacy is associated with low stress. Seniors are more vulnerable to stress than young adults on a psychological (see Karel, 1997), physiological (see McEwen and Norton Lasley, 2002), and immunological level (see Hawkley and Cacioppo, 2004). Yet, throughout life seniors have found ways to cope with familiar stressors, and this might be a factor why seniors might be more stressed when interacting with unfamiliar digitised systems, because time to find ways to cope with new stressors is limited and costly. Within the computer domain, seniors generally are less experienced (see Brynin et al., 2004) and confident about their judgements (Marquié et al., 2002), than young adults. Czaja et al. (2006) also found that older and middle-aged adults had lower self-efficacy with respect to use of computers, yet they also found that seniors had more computer anxiety than did younger adults. Computer-based work is related to stress in seniors (Birdi and Zapf, 1997; Czaja and Sharit, 1993), although Birdi and Zapf (1997) have not studied this experimentally and Czaja and Sharit (1993) focused mainly on mental workload. Within seniors, gender differences have been found in computer anxiety; female seniors report more computer anxiety than males (see Czaja et al., 2006; Karavidas et al., 2005). Several scholars suggested that stress affects, and is affected by, interface use (Hamborg and Grief, 2003; Hawthorn, 2000). In particular, older users could be negatively affected by stress during computer interaction (see, Hawthorn, 2000; Nap et al., 2005), yet empirical evidence is lacking. It is still unclear which mechanisms play a role in stress during computer interaction. Moreover, support systems that increase computer self-efficacy and decrease stress during interaction are still in their infancy. We therefore present an empirical study in which the combined effect of system complexity and self-efficacy on performance and stress is examined.

\section{Method}

Performance feedback may be an instrument in influencing someone's level of self-efficacy. In a study by Compeau and Higgens (1995), it was found that encouragement by others enhances computer self-efficacy and outcome expectancies. Positive feedback may increase self-efficacy; negative feedback may lower self-efficacy. To test such instruments to influence self-efficacy, and to gather an understanding about the role of stress and the mechanisms behind stress in senior computer interaction, we performed an experiment to investigate the joint effect of system complexity and self-efficacy on performance and stress.

\subsection{Experimental design}

An $(2 \times 2)$ incomplete counterbalanced mixed groups design was employed, with system complexity (2 levels) and performance feedback (2 levels) as fixed factors, and 
participant as random factor. Self-efficacy and perceived stress were measured by self-reports. Task performance was measured by effectiveness and efficiency (see measures section).

\subsection{Participants}

Thirty seniors $\left(M_{\text {age }}=71.04 ; S D_{\text {age }}=5.35\right.$ age range from 64 to 81 years; 17 female $)$ participated in the experiment at the Grevelingen Care Centre in Den Bosch (the Netherlands). In respect to education levels, $64.3 \%$ had finished high school and $35.7 \%$ an education level similar to college and university. The participants indicated to be subjectively healthy $(M=7.55 ; S D=1.29)$ on an 11-point Likert scale ranging from very bad health $(0)$ to very good health (10). Criteria for participation were: familiarity with the English language, subjectively healthy, and having moderate experience with PCs (beside Microsoft Word, they also used other programs).

\subsection{Material}

The experiment was conducted on a Dell latitude D800 laptop with a Pentium $\mathrm{M}$ processor and with a $15.4^{\prime \prime}$ wide screen $(1280 \times 800$ pixel resolution). The low-complexity system and the high-complexity system (see Figure 1) were used as the platforms on which the participants performed search tasks.

Figure 1 Low (left) and high (right) complexity art image retrieval system (see online version for colours)
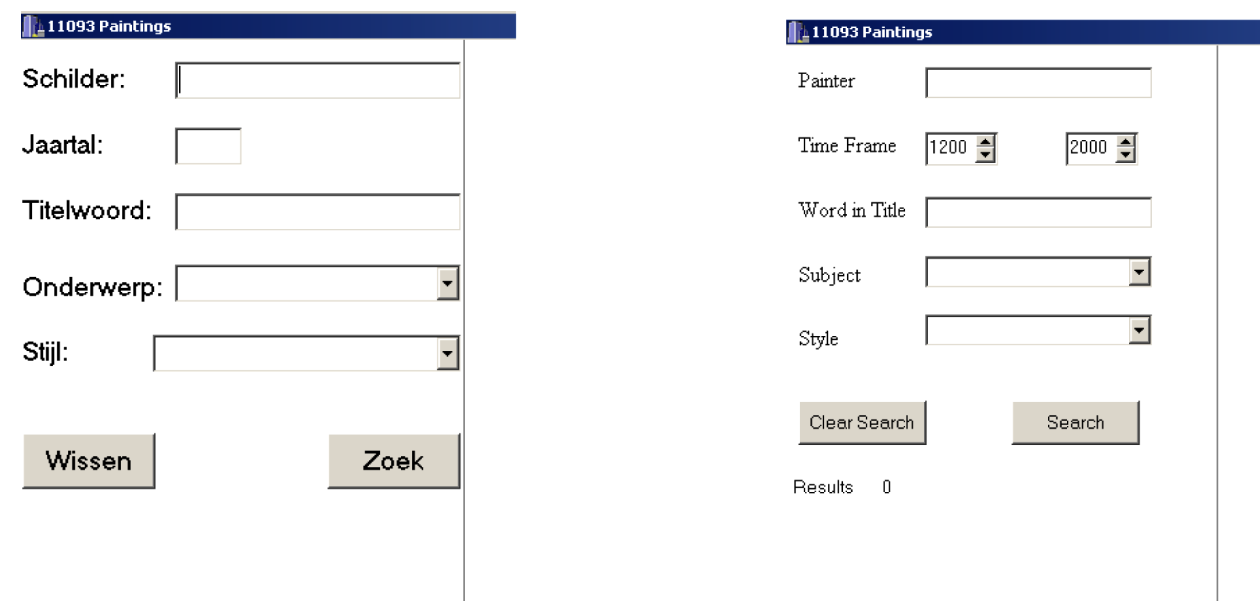

\subsection{Tasks}

Two matching sets of four practice search tasks were to be completed on the two search interfaces. The practice search tasks served to make it possible to give feedback and feed-forward information about task performance. The search tasks concerned the name of a painter (single task) and the title of a painting plus three other paintings made by the same painter (compound task), to be done two times each. A single task implied using the search interface once, for example: "Find a painting of a dog". A compound task implied 
using the search interface twice: "Who painted "Coymans"" and "Who painted "Ramparts"'? After a participant filled in or selected a search word on the image retrieval system (e.g., 'Coymans' at the 'Titelwoord' or 'Word in Title' fill-in box, see Figure 1), the search button could be pressed, and then matching art images were presented on screen at the right of the search interface. To start with a new single search task, or the second search task in a compound task, 'Wissen' or 'Clear Search' could be pressed, which cleared all the fill-in boxes and the art images at the right of the search interface.

Two matching sets of twelve search tasks had to be completed on the two systems. The twelve search tasks served to compare the task performance of the seniors on the low- and high-complexity systems, and to examine the effect of induced expected task performance and complexity on stress and expected task performance over time. The search tasks in each set consisted of six single and six compound tasks. The single tasks concerned the title of a painting, the subject of a painting, the year of creation, the style of a painting, and two replications of painter name and subject. The compound tasks concerned the title of a painting plus two other paintings made by the same painter, the year of creation of two paintings, the style of two paintings, the number of paintings available of two painters, the subject of two paintings, and the titles of two paintings.

\subsection{Manipulations}

Task performance was manipulated by system complexity (see Figure 1). Two retrieval interfaces were used which were validated, one as a high-complexity and the other as a low-complexity retrieval system for seniors (see, Nap et al., 2005; Nap, 2008). In that study, stress was observed when seniors performed search tasks on the high-complexity system, while no stress was observed when seniors performed search tasks on the low-complexity system. Higher complexity is in four aspects:

- $\quad$ use of foreign language vs. native language

- use of a time period concept with two values vs. a simple year concept

- denoting the time period using the more abstract concept of 'frame' instead of the more apt basic concept of 'period'

- $\quad$ smaller font sizes and surface areas.

In the high complexity system, the font size was 12 (in points), compared to 14 in the low-complexity system. Furthermore, the height of the 'Search' and 'Clear Search' buttons was reduced by $25 \%$, reducing the surface area from 4000 to 3000 pixels.

Self-efficacy was manipulated by performance feedback. Self-efficacy or expected task performance was induced by fictitious feedback, comparison- and feed-forward information. To induce low expected task performance, a performance graph was shown (see Figure 2) and the participants were told by the experimenter: "The green line represents the score of 114 other persons and the red line represents your score. You did not perform well. You performed worse than the other persons did." A button labelled 'Calculate Prognosis' was pressed by the experimenter and the participants were told: "I do not expect you to perform well." To induce high expected task performance, 
a performance graph was shown and the participants were told: "The green line represents your score and the red line represents the score of 114 other persons. You performed well. You performed better than the other persons did." The button 'Calculate Prognosis' was pressed and the participants were told: "I expect you to perform well."

Figure 2 Negative performance outcome graph (upper line is green, bottom line is red) (see online version for colours)

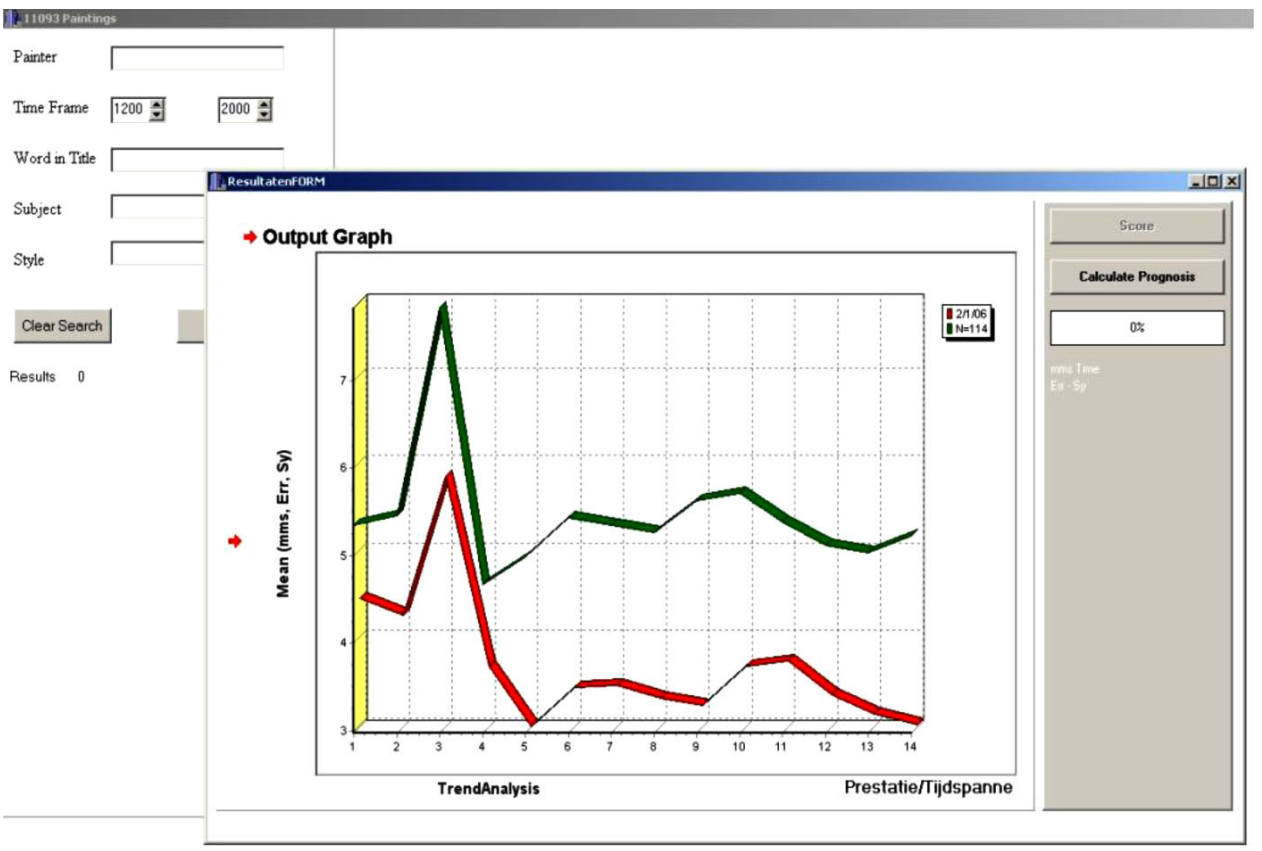

\subsection{Measures}

Perceived Stress was measured three times (Pre, Post1, and Post 2 ) by a stress scale with four items (stressed, tensed, irritated, and nervous). The Pre measurement was conducted before the First Tasks (practice set) were performed. Performance feedback was given right after the First Tasks were performed, followed by the Post1 measurement. The Post 2 measurement was conducted after the participants performed the Second Tasks (12 search tasks). The stress scale items had to be rated on an 11-point scale $(0=$ not at all, $10=$ totally). The reliability of the scale represented by mean Cronbach's alpha was $0.81^{1}$.

Self-Efficacy was also measured three times (Pre, Post1, Post2) by a question that probed their expected task performance on an 11-point scale ranging from 0 (very unlikely) to a 100 (very likely) with 10 unit intervals (see Wiedenfeld et al., 1990). The scale reflects the subjective probability that a set value can be met with the available resources.

Task Performance was measured by Efficiency and Effectiveness (ISO 9421-11, 1998). Effectiveness was measured by the number of search tasks completed correctly, and efficiency was measured by total task time. When a participant was unable to 
perform a task within the time limit of the specific task, one minute for the single task and two minutes for the compound task, the time limit was coded as the efficiency score.

\subsection{Procedure}

The participants received by mail an informed consent form and a questionnaire designed to collect their characteristics. On arrival, the signed informed consent form and questionnaire were registered and after this, the participants performed a preliminary test in which they had to type their own name in a box and had to press a button on the screen with the mouse. This test was introduced to make sure that all participants had basic knowledge of computer input devices. Information was given about the experimental procedure and it was explicitly stated that they were allowed to stop the experiment whenever they wanted. After this the participants were given a short introduction to the search tasks they were to perform, their expected task performance was measured (pre-measurement), and this was followed by four practice search tasks. Two of the practice tasks were single and two were compound; both tasks had a time limit of one minute. From a pilot study, in preparation for the experiment, it appeared that if a correct response is produced, it will be produced within these time limits. Negative or positive feedback was given about their performance (see Manipulations). The practice search tasks served to make it possible to give feedback and feed-forward information about task performance. Their expected task performance was measured again (post1-measurement), and after that subjective stress was measured (post1-measurement). Next, participants carried out the twelve search tasks. Time limits were one minute for the single tasks and two minutes for the compound tasks. This was followed by measurement of subjective stress (post2-measurement). After this expected task performance was measured (post2-measurement). The participants had a five-minute break to relax and after that, the procedure was repeated for the other complexity system. The post2-measurement of acute stress of the first (preceding) condition was used as the pre-measurement of the second (following) condition. Finally, the participants were debriefed. Information was given about the nature and goal of the research. The performance feedback screen was shown again and it was explicitly stated that the feedback given was fictitious. The total experiment took about one hour and thirty minutes per participant and all participants were paid $€ 10$ as compensation for their time.

\section{Results}

\subsection{Task performance}

To check whether there was a difference in task performance between both complexities, between conditions (first half ' 1 ' vs. second half of the experiment ' 2 '), and between both types of performance feedback (positive vs. negative), a three-way ANOVA was performed on Task Performance (Efficiency \& Effectiveness) with Condition, Feedback and Complexity as fixed factors. Only a significant effect was found on Condition $(F(1,52)=5.22, p=0.03)$. Feedback has no effect on Efficiency. Inspection of means shows faster task performance in condition 2, which is the second half of the experiment. With Effectiveness there are no significant effects, yet, Condition and Complexity have 
$\mathrm{p}$ values that are approaching significance: 0.08 and 0.06 respectively. Inspection of means shows an increase in the second half with low complexity. In conclusion: Complexity and Condition have an effect on performance, Feedback does not.

\subsection{Self-efficacy}

A Linear Mixed Models Analysis (LMMA) was performed on Self-Efficacy with Time (Pre, Post1, and Post2) and Complexity (low vs. high) as within-groups factors, Performance Feedback (positive vs. negative) as between-groups factor and participant number as random factor. A significant effect was found of Performance Feedback on Self-Efficacy $[F(1,170.5)=9.04, p=0.00]$, i.e., the manipulation worked. Furthermore, a significant effect was found of Complexity on Self-Efficacy $[F(1,142.4)=11.04$, $p=0.00]$.

Contrast analysis revealed that Self-Efficacy was rated significantly higher right after (Post1) positive performance feedback was given $\left[M_{\text {Post1 }}=51.73(3.89)\right]$ than before (Pre) positive performance feedback was given $\left[M_{\mathrm{Pre}}=46.43\right.$ (3.89)]. In addition, Self-Efficacy was rated significantly lower right after negative performance feedback was given $\left[M_{\text {Post1 }}=29.19(3.98)\right]$ than before negative feedback was given $\left[M_{\text {Pre }}=52.44\right.$ (3.98)], see Figure 3.

Figure 3 Self-Efficacy measured by self-reports $(0=$ very unlikely, $100=$ very likely, SE indicated in graph) as a function of Performance Feedback (Positive and Negative) and Time (Pre, Post1, and Post2) (see online version for colours)

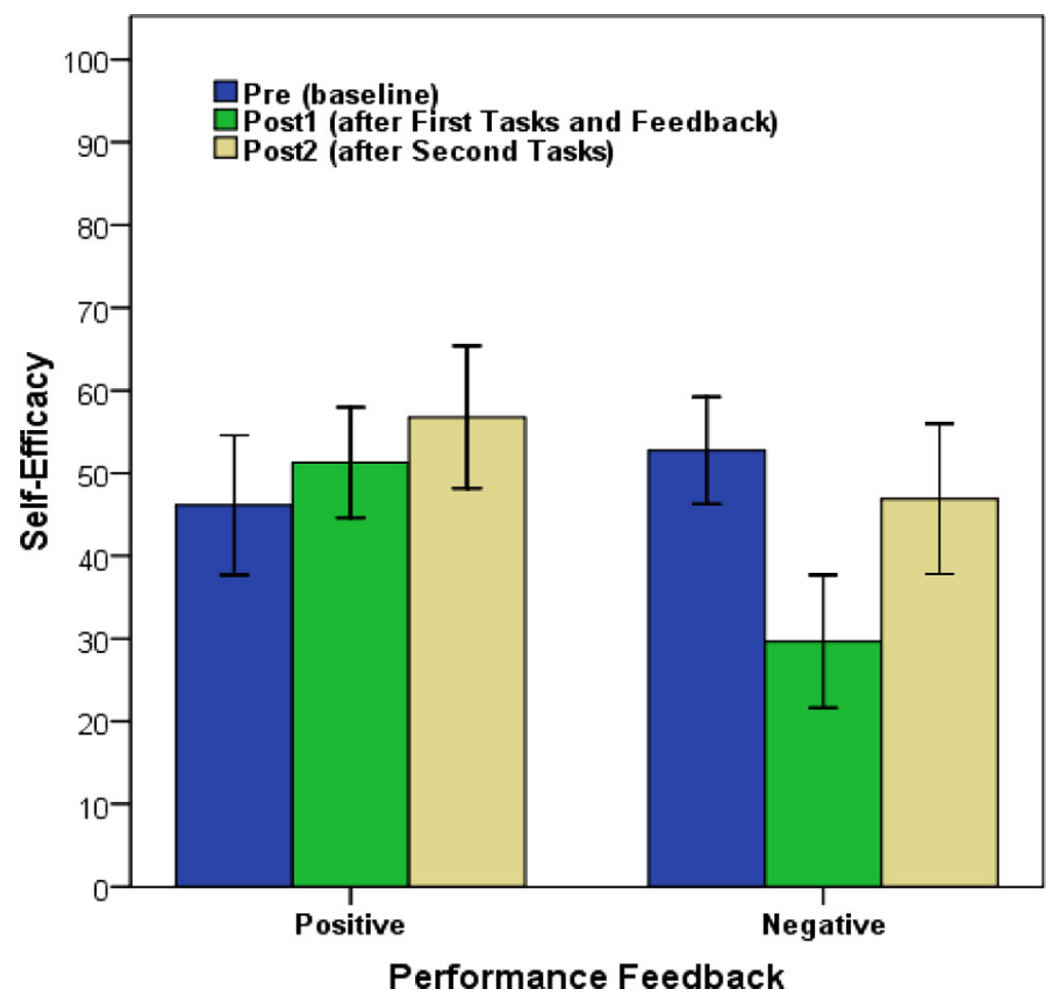


When Complexity was low, contrast analysis showed that Self-Efficacy was rated significantly lower on Post1 $\left[M_{\text {Post1 }}=45.00\right.$ (3.81)], but significantly higher on Post2 $\left[M_{\text {Post2 }}=58.67(3.81)\right]$ than Pre $\left[M_{\text {Pre }}=49.67\right.$ (3.81)]. Furthermore, when Complexity was high, contrast analysis on Self-Efficacy showed that Self-Efficacy was rated significantly lower on Post1 $\left[M_{\text {Post1 }}=35.92(3.82)\right]$ and on Post2 $\left[M_{\text {Post2 }}=44.97(3.82)\right]$, than Pre $\left[M_{\text {Pre }}=49.20(3.82)\right]$.

\subsection{Perceived stress}

A Linear Mixed Models Analysis (LMMA) was performed on Perceived Stress with Time and Complexity as within-groups factors, Performance Feedback as betweengroups factor and Participant Number as random factor.

No significant effect was found of Complexity on Perceived Stress $[F(1,142.0)=0.27 ; p=60]$ and of Performance Feedback on Perceived Stress $[F(1,53.5)=86 ; p=0.36]$. Results showed only a significant interaction effect for Time and Performance Feedback on Perceived Stress $[F(2,142.0)=3.97 ; p=0.02]$. Contrast analyses on Perceived Stress showed that Perceived Stress was rated significantly higher after negative performance feedback was given on Post1 $\left[M_{\text {Post1 }}=2.81(0.39)\right]$ and on Post $\left[M_{\text {Post2 }}=2.55(0.39)\right]$, than Pre $\left[M_{\text {Pre }}=1.99(0.39)\right]$, see Figure 4.

Figure 4 Perceived Stress measured by self-reports $(0=$ not at all, $10=$ totally, SE indicated in graph) as a function of Performance Feedback (Positive and Negative) and Time (Pre, Post1, and Post2) (see online version for colours)

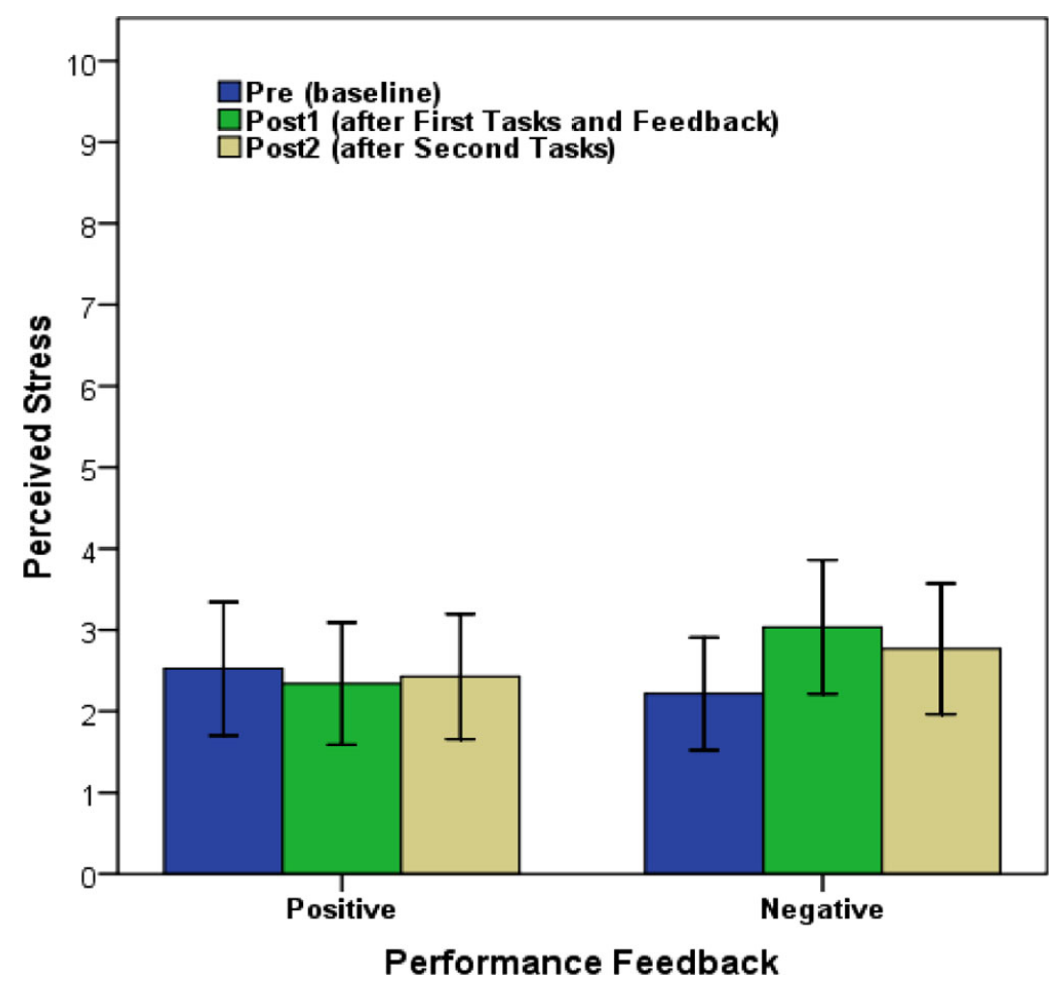




\subsection{Self-efficacy on stress}

To test whether Self-Efficacy influenced Perceived Stress, LMMAs on Perceived Stress were repeated with Self-Efficacy as a covariate. Results revealed that Self-Efficacy significantly influenced Perceived Stress $[F(1,153.3)=13.89 ; p=0.00]$, and the interaction effect for Time and Performance Feedback on Perceived Stress disappeared $[F(2,142.0)=0.86 ; p=0.43)$. A Sobel test (Sobel, 1982, 1986) was performed which indeed revealed a highly significant mediation by Self-Efficacy $[z=2.38 ; p=0.00]$. Figure 5 presents the effect of Self-Efficacy on Perceived Stress; Perceived Stress decreased with increasing Self-Efficacy.

Figure 5 Perceived Stress measured by self-reports as a linear function of Self-Efficacy (dotted lines represent confidence interval of the mean) (see online version for colours)

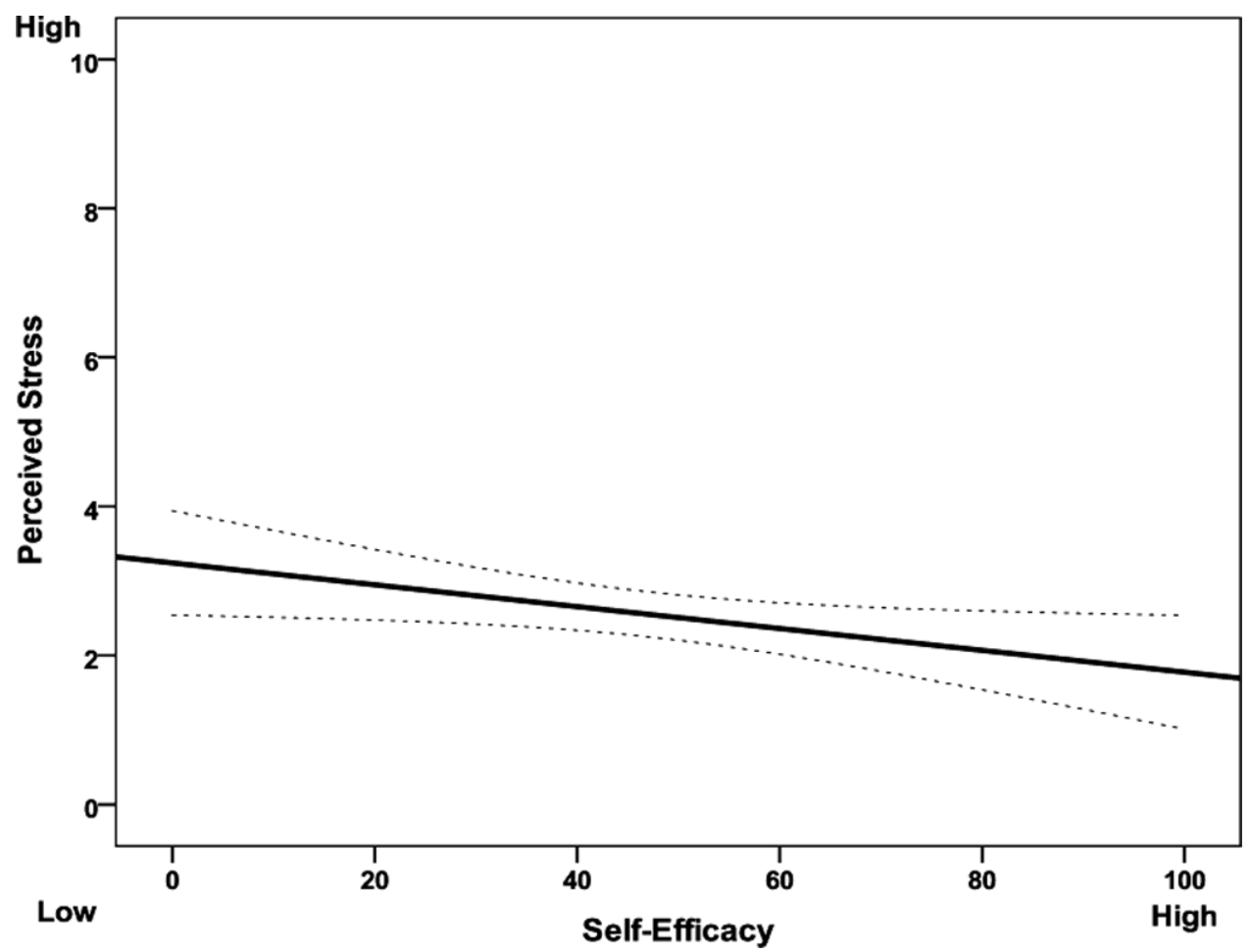

\section{Discussion}

Results revealed that seniors' self-efficacy in computer-related tasks is influenced by performance feedback and the complexity of a system. To increase seniors' confidence during computer interaction, it is advised to provide them with positive performance feedback and low system complexity. Furthermore, it was found that increasing self-efficacy decreases seniors' stress experience during interaction. In this study, no relation was found between system complexity and perceived stress. Whether a stressor, e.g., a high complexity system, is threatening depends on the individual appraisal of the situation. This appraisal is based on previous experience and expectations of the outcome 
(Ursin and Eriksen, 2004), i.e., self-efficacy. It was found that the complexity of a digitised system does not influence stress, but the self-efficacy or the expected task performance, induced by feedback information about performance does influence stress. Similar results have been found by Eriksen and Ursin (1999) on health complaints in a study of 1060 people working in the Norwegian postal service. It was found that the objective possibility of having control, which was operationalised by, among other things, skills and task variety, had a lower impact on subjective health complaints than coping. Coping was defined as an expectancy of positive outcome and was operationalised by, among other things, being optimistic about outcomes and approaching difficult situations.

The present study showed that the expectancies seniors have about how they will perform on a computer system decreases when they receive negative feedback and feed-forward information about their performance. This finding could have practical implications for system designers, who could implement affective support in the form of positive feedback messages in (senior) computer software, or at least, to avoid negative feedback messages. Similar to a virtual coach that motivates athletes to exercise behaviour (see Eyck et al., 2006); seniors' self-efficacy could be increased by a virtual coach or teacher during computer interaction. Similar to the conclusions of Compeau and Higgens (1995), it is important to provide computer users with positive outcome expectancies, and develop support that increases coping and the level of self-efficacy. Induced positive outcome expectancies might encourage seniors to interact with new media, and it will show them benefits in terms of higher self-efficacy. In addition, complexity has an effect on self-efficacy, in other words: when the costs are reduced by a low-complexity system, trust in the ability to perform is increased.

Future research could explore the extent to which self-efficacy support decreases physiological stress in senior computer interaction (e.g., level of cortisol, heart rate variability, palmar sweating). In addition, although we measured a decrease in perceived stress by increasing self-efficacy, the mean stress values were low. This was possibly due to the relatively safe home environment in which the experiments were performed and the fact that stress manipulation by induced expected task performance was quite mild for ethical reasons. Future research could explore, for example by experience sampling or diary studies over time, the level of stress and frustration seniors experience in using digitised media and when they experience stress. Knowledge from the field of persuasive technologies (IJsselsteijn et al., 2006) could be used to design a more effective performance feedback, which should be explored in future studies to maximise satisfying computer interaction for the senior population. Additionally, it would be valuable to understand which coping mechanisms seniors employ when they experience stress while using new media. It is likely that seniors vary in the way they cope with stress during computer interaction, which demands the development of personalised self-efficacy support systems.

In conclusion, to increase self-efficacy and to decrease stress in senior computer interaction, it is advised to support seniors during computer interaction with positive performance feedback. Seniors' stress experience increased and self-efficacy decreased when they were provided with negative performance feedback. Overall, negative performance feedback should rather be avoided in senior computer interaction. 


\section{References}

Bandura, A. (1977) 'Self-efficacy: Toward a unifying theory of behavioural change', Psychological Review, Vol. 84, pp.191-215.

Bessière, K., Newhagen, J.E., Robinson, J.P. and Shneiderman, B. (2006) 'A model for computer frustration: the role of instrumental and dispositional factors on incident, session, and post-session frustration and mood', Computer in Human Behavior, Vol. 22, pp.941-961.

Birdi, K.S. and Zapf, D. (1997) 'Age differences in reactions to errors in computer-based work', Behaviour \& Information Technology, Vol. 16, pp.309-319.

Brynin, M., Raban, Y. and Soffer, T. (2004) e-Living: Life in a Digital Europe, Chapter 5: The New ICTs: Age, Gender and the Family, Obtained through the Internet: http://www.eurescom.de/e-living/deliverables/e-liv-D14-Ch5-Family.pdf, [accessed 4/11/ 2010].

Compeau, D.R. and Higgens, C.A. (1995) 'Self-efficacy: development of a measure and initial test', MIS Quarterly, Vol. 19, pp.189-211.

Czaja, S.J. and Lee, C.C. (2007) 'The impact of aging on access to technology', Universal Access in the Information Society, Vol. 5, pp.341-349.

Czaja, S.J. and Sharit, J. (1993) 'Stress reactions to computer-interactive tasks as a function of task structure and individual differences', International Journal of Human-Computer Interaction, Vol. 5, pp.1-22.

Czaja, S.J., Charness, N., Fisk, A.D., Hertzog, C., Nair, S.N., Rogers, W.A. and Sharit, J. (2006) 'Factors predicting the use of technology: findings from the Center for Research and Education on Aging and Technology Enhancement (CREATE)', Psychology and Aging, Vol. 21, pp.333-352.

Eriksen, H.R. and Ursin, H. (1999) 'Subjective health complaints: is coping more important than control?', Work \& Stress, Vol. 13, pp.238-252.

Eyck, A., Geerlings, K., Karimova, D., Meerbeek, B., Wang, L., IJsselsteijn, W., De Kort, Y, Roersma, M. and Westerink, J. (2006) 'Effect of a virtual coach on athletes' motivation', in IJsselsteijn, W., De Kort, Y., Midden, C., Eggen, B. and Van den Hoven, E. (Eds.): First International Conference on Persuasive Technology for Human Well-Being, Springer, Berlin, pp.158-161.

Folkman, S., Lazarus, R.S., Dunkel-Schetter, C., DeLongis, A. and Gruen, R.J. (1986) 'The dynamics of a stressful encounter: cognitive appraisal, coping, and encounter outcomes', Journal of Personality and Social Psychology, Vol. 50, pp.992-1003.

Freudenthal, D. (2001) 'Age differences in the performance of information retrieval tasks', Behaviour \& Information Technology, Vol. 20, pp.9-22.

Hamborg, K.C. and Grief, S. (2003) 'New technologies and stress', in Schabracq, M.J., Winnubst, J.A.M. and Cooper, C.L. (Eds.): The Handbook of Work and Health Psychology (2nd ed.), John Wiley \& Sons Ltd., Chichester, p.211.

Hawkley, L.C. and Cacioppo, J.T. (2004) 'Stress and the aging immune system', Brain, Behavior, and Immunity, Vol. 18, pp.114-119.

Hawthorn, D. (2000) 'Possible implications of aging for interface designers', Interacting with Computers, Vol. 12, pp.507-528.

IJsselsteijn, W., De Kort, Y., Midden, C., Eggen, B. and Van den Hoven, E. (2006) 'Persuasive technology for human well-being: setting the scene', in IJsselsteijn, W., De Kort, Y., Midden, C., Eggen, B. and Van den Hoven, E. (Eds.): First International Conference on Persuasive Technology for Human Well-Being, Springer, Berlin, pp.1-5.

ISO 9241-11 (1998) 'Ergonomic requirements for office work with visual display terminals (VDTs) Part 11: Guidance on usability', International Organization for Standardization, Geneva. 
Karavidas, M., Lim, N.K. and Katsikas, S.L. (2005) 'The effects of computers on older adult users' Computers in human behavior, Vol. 21, pp.697-711.

Karel, M.J. (1997) 'Aging and depression: vulnerability and stress across adulthood', Clinical Psychology Review, Vol. 17, pp.847-879.

Lazarus, R.S. and DeLongis, A. (1983) 'Psychological stress and coping in aging', American Psychologist, Vol. 38, pp.245-254.

Marquié, J.C., Jourdan-Boddaert, L. and Huet, N. (2002) 'Do older adults underestimate their actual computer knowledge?', Behaviour \& Information Technology, Vol. 21, pp.273-280.

McEwen, B. and Norton Lasley, E. (2002) The End of Stress as We Know it, Joseph Henry Press, Washington.

Morrell, R.W. (ed.) (2002) Older Adults, Health Information and the World Wide Web, Lawrence Erlbaum Associates, Mahwah, New Jersey.

Nap, H.H. (2008) Stress in Senior Computer Interaction, PhD Thesis, Technische Universiteit Eindhoven, Eindhoven, The Netherlands.

Nap, H.H., De Greef, H.P. and Bouwhuis, D.G. (2005) 'Access for all by cognitive engineering', Gerontechnology, Vol. 3, p.259.

Neerincx, M.A., Lindenberg, J., Rypkema, J.A. and Van Besouw, N.J.P. (2000) 'A practical cognitive theory of Web-navigation: Explaining age-related performance differences', CHI2000.

Sayers, H. (2004) 'Desktop virtual environments: a study of navigation and age', Interacting with Computers, Vol. 16, pp.939-956.

Sobel, M.E. (1982) 'Asymptotic confidence intervals for indirect effects in structural equation models', in Leinhardt, S. (Ed.): Sociological Methodology 1982, American Sociological Association, Washington, DC, pp.290-312.

Sobel, M.E. (1986) 'Some new results on indirect effects and their standard errors in covariance structure models', in Tuma, N. (Ed.): Sociological Methodology 1986, American Sociological Association, Washington, DC, pp.159-186.

UN (2008) World Population Prospects, The 2008 Revision, United Nations Department of Economic and Social Affairs, Population Division, Obtained through the Internet: http://www.un.org/esa/population/publications/wpp2008/wpp2008_highlights.pdf, [accessed $4 / 11 / 2010]$.

Ursin, H. and Eriksen, H.R. (2004) 'The cognitive activation theory of stress', Psychoneuroendocrinology, Vol. 29, pp.567-592.

Ursin, H., Baade, E. and Levine, S. (Eds.) (1978) Psychobiology of Stress: A Study of Coping Men, Academic Press, New York.

Wiedenfeld, S.A., O'Leary, A., Bandura, A., Brown, S., Levine, S. and Raska, K. (1990) 'Impact of perceived self-efficacy in coping with stressors on components of the immune system', Journal of Personality and Social Psychology, Vol. 59, pp.1082-1094.

Xie, B. (2002) 'Older adults, computers and the Internet: Future directions', Gerontechnology, Vol. 2, pp.289-305.

\section{Note}

${ }^{1}$ A Cronbach's Alpha is used to measure the internal consistency reliability of the used questionnaire. A reliability of 0.70 or higher is considered good, 0.60 to 0.70 as acceptable. 